\title{
SOCIAL SUPPORT AMONG MALE UNDERGRADUATES: A SYSTEMATIC REVIEW
}

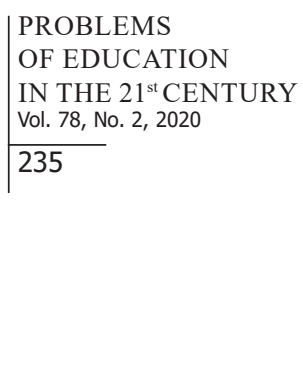

PROBLEMS

IN THE $21^{\text {st }}$ CENTURY

Vol. 78, No. 2, 2020

235

\author{
James Morris III \\ Lewis University, United States \\ E-mail: professorjmiii@gmail.com
}

\begin{abstract}
Although researchers have conducted multiple studies on social support among male undergraduates, a gap was identified in the lack of systematic reviews of literature synthesizing their findings. The purpose in this systematic review was to obtain an understanding of recent findings on social support among male undergraduates. To identify relevant literature, a search strategy was developed consisting of six criteria for inclusion, which yielded a total of 30 studies from multiple databases. Findings showed an overall positive impact of social support on psychological outcomes, academic achievement, and technology use among male undergraduates. The findings also revealed a diverse range of sources of social support as well as variations based on gender. In addition to addressing the identified gap in the research, findings from the review may help teachers, educational policymakers, educators, and scholars identify relevant patterns that could be used to note important dimensions within which possible interventions could be introduced to promote desired outcomes.
\end{abstract}

Keywords: academic achievement, male undergraduates, social support, systematic review, technology use.

\section{Introduction}

The experience of undergraduates can be both distressing and satisfying. Undergraduates may find themselves facing multiple demands and coping with challenging programs (Vungkhanching, Tonsing, \& Tonsing, 2016). Students may experience challenges due to individual goals, adjustment in the new atmosphere, interactions with professors, financial strain, and academic pressure (Marhamah \& Hamzah, 2016). Research findings suggest that students may experience depression, anxiety, and psychological distress while studying as undergraduates (Abu-Kaf, Shahar, Noyman-Veksler, \& Priel, 2018; Marhamah \& Hamzah, 2016; Roohafza et al., 2016; Tang \& Dai, 2018; Vungkhanching et al., 2016). The well-being of undergraduates may be at risk, with significant social consequences, due to academic problems, familial separation, and alteration in location (Vungkhanching et al., 2016). Undergraduates experience not only external challenges but also cognitive and social transformation, which has led researchers to emphasize the need for more focus on this particular group (Rodríguez, Tinajero, \& Páramo, 2017). Researchers have also pointed out that the performance of individuals in the future cannot be predicted solely on the basis of attainments in the past, skills, and knowledge, and there is a need to focus on strategies for psychological coping in response to potential distress (Bai, Chao, \& Wang, 2018; Li, Han, Wang, Sun, \& Cheng, 2018). In this regard, research attention has begun to be directed towards the social mechanism known as social support, which highlights the significance of the social aspect of a person (Marhamah \& Hamzah, 2016). Researchers have presented social support as a significant element in encouraging undergraduates' educational attainment and in reducing their psychological stress (Bai et al., 2018; Li et al., 2018; Marhamah \& Hamzah, 2016; Vungkhanching et al., 2016). 
PROBLEMS

OF EDUCATION

IN THE $21^{\text {st }}$ CENTURY

Vol. 78, No. 2, 2020

236

Social support can be described as an individual's perception or reception from the immediate environment of psychological and social support (Lin, 2016). Examples of such support include assistance, care, and respect (Lee \& Goldstein, 2016). Social support may be perceived, which highlights the beliefs and perceptions that an individual might have regarding the quality and quantity of their available social support (Rios \& Eaton, 2016). Researchers have described social support in terms of interpersonal interactions within one's social groups and the impressions and perceptions one might have regarding it, and noted that perception of social support is more significant than actual social support received (Bhochhibhoya, Dong, \& Branscum, 2017). Social support, as perceived, describing the belief of a person regarding the availability of social support, can be negative or positive, and indicates a person's needs (Vungkhanching et al., 2016). As a result, social support perceived by an individual is multidimensional and complex, and includes assessment, informational, and emotional support. Noting social support's important role among undergraduates, researchers have conducted multiple studies on social support examining the association between social support and academic achievement, social support and technology use, social support and psychological outcomes, source of social support, and gender differences regarding social support. A systematic review of research on these themes among male undergraduates could help enhance the current level of knowledge regarding the association between social support and the most relevant elements in the lives of male undergraduates.

\section{Research Problem}

Although there is significant research examining the association between role of social support and academic achievement, technology use, psychological outcomes, source of social support, and gender differences regarding social support among college students, there is currently a lack of a systematic review of literature on social support among male undergraduate with respect to these elements. Such a systematic review of research could help enhance the current level of knowledge regarding the association between social support and the most relevant elements in the lives of male undergraduates.

\section{Review Purpose}

The purpose in this systematic review was to contribute to filling a gap identified in the existing literature through a systematic review of literature published in the preceding five years on social support among male undergraduates. The synthesis of latest studies on the topic will help teachers, educational policymakers, educators, and scholars identify the most relevant patterns in the literature on social support among male undergraduates that can be used to note important dimensions within which possible interventions can be introduced to enhance social support and improve male undergraduates' well-being and academic achievement. Specifically, there were two broad purposes in this systematic review. First, the aim was to provide a summary of the existing peer-reviewed empirical research in which the variable of social support has been examined in the context of male undergraduates, while noting the sample size, location of the study, data collection tools, and outcomes. Secondly, the aim was to provide a discussion synthesizing the findings from the research published within the preceding five years on social support among male undergraduates. In alignment with the research purpose, the following research question was used to guide the current systematic review:

What findings can be identified from the recent literature on social support among male undergraduates? 


\section{Research Methodology}

\section{Search Strategy}

The researcher identified the relevant literature for this systematic review in three phases. In the first phase, a systematic literature search strategy was developed, which was then implemented on multiple databases, namely PubMed, ERIC, ScienceDirect, and JSTOR. The inclusion criteria required the studies to be recent. As a result, time period specified on each database was between January 2015 to December 2019. Another inclusion criterion was for each study to be included to be peer-reviewed and in English, which resulted in the exclusion of books and reports as well as those publications that were not in English. It was important that the sample in the included studies represented undergraduates and included male participants. Studies that did not meet these requirements were excluded. As this was a systematic review of empirical research, literature reviews were excluded. Finally, relevance to the research question was another inclusion criterion. For the identification of relevant research, the following search terms were used: undergraduates OR male OR social support OR academic achievement OR technology OR psychological outcomes OR source social support OR gender differences. The overall results from the specific databases were screened manually through title at first and then through abstract, followed by a review of the full text. Based on this strategy, papers that were potentially relevant for the systematic review were identified, chosen, and read with the goal of examining whether they adhered to the inclusion criteria set for the current review. Additionally, the references within relevant papers were also examined to identify papers for inclusion in the review. The implementation of the search strategy is illustrated in Figure 1.

\section{Data Extraction}

In order to extract data from the relevant papers identified, the researcher developed a spreadsheet. Due to the high variation found among the studies regarding measures and samples, it was not feasible to conduct a meta-analysis. Instead, for this systematic review, the researcher adopted a non-quantitative approach which included synthesis of results and the presentation of the findings in the form of text and tables. To measure the quality of the studies included in the review, a quality rating scale was used. For this purpose, eight items were assessed, which examined external, statistical, and internal validity of the research studies. Internal validity was measured through four items targeting the reliability and validity of the social support variable, the examination of social support variable, and the correction regarding covariates' confounding influence on social support. With respect to statistical validity, two items were used, which included the presence of sufficient size of sample and proper statistical tests. With respect to external validity, two items were used which included the presence of adequate information regarding demographic characteristics of the participants, especially gender, and methods for sampling. 
James MORRIS III. Social support among male undergraduates: A systematic review

PROBLEMS

OF EDUCATION

IN THE $21^{\text {st }}$ CENTURY

Vol. 78 , No. 2, 2020

238

Figure 1

Search strategy implementation process to identify relevant studies

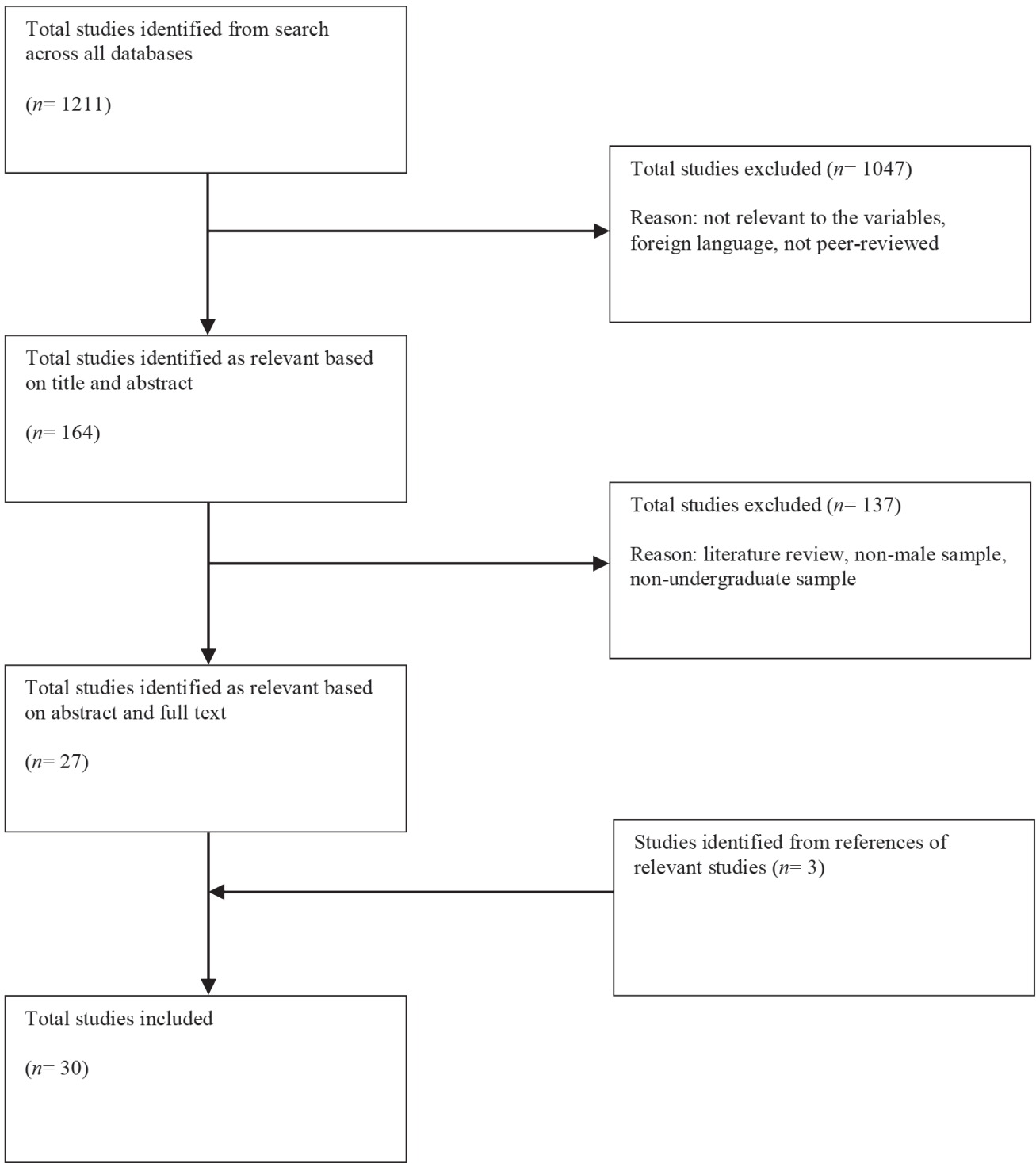

\section{Research Results}

A total of 30 studies were found that adhered to the inclusion criteria set for the systematic review. Of these, 16 focused on social support and psychological outcomes (AbuKaf et al., 2018; Adamczyk, 2015; Bíró, Veres-Balajti, \& Kósa, 2016; Ceglarek \& Ward, 2016; Frison \& Eggermont, 2015; Kim, Kim, \& Lee, 2016; Llamas, Morgan Consoli, Hendricks, \& Nguyen, 2018; Marhamah \& Hamzah, 2016; Ng, Wang, \& Chan, 2017; Roohafza et al., 2016; Tang \& Dai, 2018; Vungkhanching, Tonsing, \& Tonsing, 2016; Wang, Sun, \& Wang, 2016; Wongtongkam, 2019; Yildırım, Karaca, Cangur, Acıkgoz, \& Akkus, 2017; You, Lim, \& Kim, 2017); 3 focused on social support and academic achievement (Bai et al., 2018; Li et 
al., 2018; Rodríguez et al., 2017); 4 focused on social support and technology use (Deechuay,

Koul, Maneewan \& Lerdpornkulrat, 2016; Gökçearslan, Uluyol \& Şahin, 2018; Shah, Siddiqui \& Ansari, 2016; Zhang et al., 2018); 4 focused on sources of social support (Bhochhibhoya et al., 2017; Chuah \& Singh, 2016; Lee \& Goldstein, 2016; Rios \& Eaton, 2016); and 3 focused exclusively on gender differences in social support (Lin, 2016; Zamani-Alavijeh, Raeesi Dehkordi, \& Shahry, 2017; Zhang, Zhapng, Zhang, Zhang, \& Feng, 2018). All studies except one were quantitative. Thus, the studies included in the review were characterized by methodological homogeneity. However, in terms of sample characteristics, such as sample size and location, and instrumentation, there was wide variation, which presented challenges in comparing the findings to arrive at conclusions.

With respect to the countries represented in the sample of the review's studies, these included Australia, Belgium, China, Pakistan, Malaysia, Korea, Israel, Iran, Indonesia, Hungary, Hong Kong, Poland, Spain, Taiwan, Thailand, Turkey, and the United States. In terms of sample, the lowest sample size of male participants in any included study was 9, while the highest sample size of male participants in any included study was 2106 . With regards to the instruments used to measure social support, there was wide variation, although Multidimensional Scale of Perceived Social Support emerged as the most used instrument to measure social support among undergraduates (Adamczyk, 2015; Frison \& Eggermont, 2015; Lee \& Goldstein, 2016; Li et al., 2018; Roohafza et al., 2016; Wongtongkam, 2019; Yıldırım et al., 2017; Zhang et al., 2018). Other instruments used to measure social support included Perceived Social Support Scale (Gökçearslan et al., 2018; Wang et al., 2016), Social Support Rating Scale (Shah et al., 2016; Tang \& Dai, 2018), Social and Emotional Health Survey (You et al., 2017; Zhang et al., 2018), MOS Social Support Survey (Ceglarek \& Ward, 2016), Multi-Dimensional Support Scale (Ng et al., 2017), Perceived Acceptance Scale (Rodríguez et al., 2017), and Social Support Questionnaire (Bai et al., 2018). Specific characteristics of the included studies are presented in Table 1. In the remainder of this section, the findings of the study are described. In the next section, a discussion pertaining to the findings will be presented.

\section{Table 1}

\section{Studies included in the systematic review}

\begin{tabular}{|c|c|c|c|}
\hline Study & Country & $\begin{array}{l}\text { Male } \\
\text { sample } \\
n\end{array}$ & Variables \\
\hline $\begin{array}{l}\text { Zamani-Alavijeh } \\
\text { et al. (2017) }\end{array}$ & Iran & 456 & $\begin{array}{l}\text { Social support, parental education and job, field of study, place of } \\
\text { residence, marital status, gender }\end{array}$ \\
\hline $\begin{array}{l}\text { Zhang et al. } \\
\text { (2018) }\end{array}$ & China & 872 & Social support, gender, resilience, psychological distress \\
\hline $\begin{array}{l}\text { Bhochhibhoya et } \\
\text { al. (2017) }\end{array}$ & $\begin{array}{l}\text { United } \\
\text { States }\end{array}$ & 148 & $\begin{array}{l}\text { Social support, close individuals (home country), close individuals } \\
\text { (United States, home country origin), close individuals (United } \\
\text { States, other country origin, close individuals (local community) }\end{array}$ \\
\hline $\begin{array}{l}\text { Zhang et al. } \\
\text { (2018) }\end{array}$ & China & 81 & $\begin{array}{l}\text { Social support, loneliness, Internet addiction, interpersonal and } \\
\text { health problems }\end{array}$ \\
\hline $\begin{array}{l}\text { Vungkhanching et } \\
\text { al. (2016) }\end{array}$ & $\begin{array}{l}\text { United } \\
\text { States }\end{array}$ & 40 & Social support, psychological distress, coping strategy \\
\hline Li et al. (2018) & China & 108 & $\begin{array}{l}\text { Social support, self-esteem, academic achievement, emotional } \\
\text { exhaustion }\end{array}$ \\
\hline $\begin{array}{l}\text { Marhamah \& } \\
\text { Hamzah (2016) }\end{array}$ & Indonesia & 149 & Social support and academic stress \\
\hline Bai et al. (2018) & Hong Kong & 620 & Social support, selflefficacy, and learning achievement \\
\hline
\end{tabular}


James MORRIS III. Social support among male undergraduates: A systematic review

PROBLEMS

OF EDUCATION

IN THE $21^{\text {st }}$ CENTURY Vol. 78 , No. 2, 2020

\begin{tabular}{|c|c|c|c|}
\hline Bíró et al. (2016) & Hungary & 9 & Social support, self-esteem, mental resilience \\
\hline $\begin{array}{l}\text { Abu-Kaf et al. } \\
\text { (2018) }\end{array}$ & Israel & 75 & Social support, depressive and somatic symptoms \\
\hline $\begin{array}{l}\text { Deechuay et al. } \\
\text { (2016) }\end{array}$ & Thailand & 231 & Gender identity, social support, computer self-efficacy \\
\hline Shah et al. (2016) & Pakistan & 82 & Internet addiction and social support \\
\hline Kim et al. (2016) & Korea & 80 & Work volition, social support, occupational engagement \\
\hline $\begin{array}{l}\text { Wang et al. } \\
(2016)\end{array}$ & China & 958 & Emotional intelligence, social support, subjective well-being \\
\hline $\operatorname{Lin}(2016)$ & Taiwan & 264 & Social support, coping style, gratitude, well-being \\
\hline $\begin{array}{l}\text { Gökçearslan et al. } \\
(2018)\end{array}$ & Turkey & 364 & Smartphone addiction, cyberloafing, stress, social support \\
\hline Tang \& Dai (2018) & China & 883 & $\begin{array}{l}\text { Socioeconomic factors, coping style, social support, depressive } \\
\text { symptoms }\end{array}$ \\
\hline $\begin{array}{l}\text { Lee \& Goldstein } \\
\text { (2016) }\end{array}$ & $\begin{array}{l}\text { United } \\
\text { States }\end{array}$ & 126 & Loneliness, stress, and social support \\
\hline You et al. (2017) & Korea & 622 & Sources of social support, psychological factors, life satisfaction \\
\hline $\begin{array}{l}\text { Rodríguez et al. } \\
\text { (2017) }\end{array}$ & Spain & 102 & $\begin{array}{l}\text { Academic achievement, perceived social support, adaptation to } \\
\text { university }\end{array}$ \\
\hline $\begin{array}{l}\text { Chuah \& Singh } \\
(2016)\end{array}$ & Malaysia & 154 & Host national students, international students, social support \\
\hline $\begin{array}{l}\text { Wongtongkam } \\
\text { (2019) }\end{array}$ & Australia & 69 & $\begin{array}{l}\text { Emotional distress, self-esteem, social support, coping methods, } \\
\text { emotional distress }\end{array}$ \\
\hline $\begin{array}{l}\text { Rios \& Eaton } \\
(2016)\end{array}$ & $\begin{array}{l}\text { United } \\
\text { States }\end{array}$ & 24 & Sources of social support, nature of social support \\
\hline $\begin{array}{l}\text { Yildırım et al. } \\
\text { (2017) }\end{array}$ & Turkey & 99 & $\begin{array}{l}\text { Education-related stress, stress coping, self-esteem, social support, } \\
\text { health status }\end{array}$ \\
\hline $\begin{array}{l}\text { Frison \& } \\
\text { Eggermont (2015) }\end{array}$ & Belgium & 438 & Facebook use, social support, depressed mood \\
\hline $\mathrm{Ng}$ et al. (2017) & Hong Kong & 97 & Social support, acculturation strategies, cross-cultural adaptation \\
\hline $\begin{array}{l}\text { Llamas et al. } \\
(2018)\end{array}$ & $\begin{array}{l}\text { United } \\
\text { States }\end{array}$ & 137 & $\begin{array}{l}\text { Intragroup marginalization, psychological distress, locus of control, } \\
\text { peer social support }\end{array}$ \\
\hline Adamczyk (2015) & Poland & 148 & $\begin{array}{l}\text { Romantic relationships status, emotional and social loneliness, } \\
\text { social support }\end{array}$ \\
\hline $\begin{array}{l}\text { Ceglarek \& Ward } \\
(2016)\end{array}$ & $\begin{array}{l}\text { United } \\
\text { States }\end{array}$ & 41 & Social support, sexual identity strength, mental health \\
\hline $\begin{array}{l}\text { Roohafza et al. } \\
\text { (2016) }\end{array}$ & Iran & 2106 & $\begin{array}{l}\text { Psychological outcomes, social support, coping strategies, } \\
\text { perceived stress, personality traits }\end{array}$ \\
\hline
\end{tabular}

\section{Social Support and Psychological Outcomes}

The focus of 16 of the 30 studies reviewed was on studying social support and psychological outcomes. Overall, researchers reported positive outcomes associated with the presence of social support on male undergraduates' psychological health, and negative outcomes 
in its absence. Vungkhanching et al. (2016), reporting on public university undergraduates in California, found that social support among undergraduates coming from their friends was negatively correlated with depression $(r=-.22, p<.05)$. With respect to anxiety, social support was found to predict $28.7 \%$ variability. In addition to depression and anxiety, a negative correlation was found between social support and stress. Higher social support from friends was reported among senior year undergraduates compared to junior, which was in turn associated with higher stress score among junior year undergraduates (mean among junior year undergraduates $=2.31$, among senior year undergraduates $=1.96$ ). Anxiety was also studied in the context of social support by Roohafza et al. (2016), who reported that, among Iranian male undergraduates, low social support was correlated with high depression and anxiety $(P<.001)$, while a negative association was found between social support and neuroticism $(P<.001)$. Social support had a negative impact on anxiety (-.05).

Similar findings to those of Vungkhanching et al. (2016) on stress, albeit in the context of Indonesian male undergraduates, were reported by Marhamah and Hamzah (2016), who found that social support was negatively correlated with stress $(r=-.46, p<.01)$. In the context of Hungarian male undergraduates, Bíró et al. (2016) also reported positive outcomes associated with social support, finding that family-derived social support resulted in 6 points increase and from peers resulted in 1point increase in the sense of coherence among the students. Regarding depression, findings like those of Vungkhanching et al. (2016) were reported by Abu-Kaf et al. (2018) based on a comparison between Bedouin Arab and Jewish Israeli students. Abu-Kaf et al. (2018) found that social support was negatively associated with depression in both group of students. Depression among undergraduates was also studied by Tang and Dai (2018), who examined it in relation to social support among Chinese undergraduates and found it to be correlated with social support independently of the students' rural or urban origin, status as one-child, or gender. Like Abu-Kaf et al. (2018) and Vungkhanching et al. (2016), Tang and Dai (2018) also identified negative association between social support and depression. Frison and Eggermont (2015) also identified negative association between social support and depression.

Other variables studied by researchers regarding psychological outcomes included loneliness, emotional intelligence, subjective well-being, work engagement, emotional distress, emotional regulation, loneliness, and self-efficacy. Regarding loneliness, Adamczyk (2015) found that, among Polish male undergraduates, students' relationship status had a significant effect on social support as perceived by the students [Wilks's $\Lambda=.70, F(3,309)=44.90, p<.001$, $\eta 2=.30$ ]. Wang et al. (2016) found that, among Chinese male undergraduates, social support was positively correlated with positive effects, along with life satisfaction and emotional intelligence $(r=.27 \sim 0.58, P=.01)$; likewise, social support was negatively correlated with negative effects along with life satisfaction and emotional intelligence $(r=-.33 \sim-0.38, p=.01)$. Overall, social support emerged as a mediating element between life satisfaction and emotional intelligence. The association between well-being and emotional intelligence was partially mediated by social support. Regarding work motivation, Kim et al. (2016) reported that, among Korean undergraduates, social support had a significant indirect effect on workplace engagement, with work volition as mediator $\left(\mathrm{c}^{\prime}=.07, \mathrm{SE}=.02, \mathrm{CI}[.03, .11]\right)$.

Regarding emotional regulation and self-efficacy, You et al. (2017) reported that, among Korean male undergraduates, social support, of which three sources were studied by the researchers (namely teacher, peer, and family) was associated with emotional regulation (teacher $b=.18, p<.001$; peer $b=.44, p<.001$; family $b=.29, p<.001$ ) and self-efficacy (teacher $b=.45, p<.001$; peer $b=.23, p<.001$; family support $b=.26, p<.001$ ). Support from family was found to be directly associated with life satisfaction $(b=.21, p<.001)$, although no direct association was found with respect to teacher and peer support.

With respect to emotional distress, Wongtongkam (2019) reported that, among Australian undergraduates, social support was a potential risk factor regarding the emergence of emotional

$\mid$\begin{tabular}{l} 
PROBLEMS \\
OF EDUCATION \\
IN THE 21 $1^{\text {st }}$ CENTURY \\
Vol. 78, No. 2, 2020 \\
\hline 241
\end{tabular} 
PROBLEMS

OF EDUCATION IN THE $21^{\text {st }}$ CENTURY Vol. 78, No. 2, 2020

242

distress, instead of being a protective factor $(\mathrm{OR}=7.58)$. Not surprisingly, it was found that social support increased gradually from first semester to last year across two sources, namely family $[F(2,109)=3.22, p=.04]$ and friends $[F(2,109)=3.57, p=.03]$. Social support, in addition to predicting risk of distress, can also serve as a predictor of stress coping among nursing undergraduates, as reported in the context of Turkey by Yildirim et al. (2017).

Three studies focused on minorities, marginalization, and cultural adaptation in the context of social support and mental health. Ng et al. (2017) examined social support's role in strategies for cultural adaptation among Chinese undergraduates studying in Hong Kong. Among male students, it was found that higher social support obtained from students' family was a significant predictor of cultural adaptation $(B=.12, p<.001)$. In the presence of low social support from friends $(B=.06, p=.354)$, cultural adaptation was not found to be associated with integration, but this altered in the presence of high $(B=.74, p<.001)$ or medium $(B=.40, p<.001)$ social support from friends. With respect to marginalization, it was found to negatively affect adaptation in the presence of low social support from friends $(B=-.93, p=.009)$. However, in the presence of high $(B=.50, p=.126)$ or medium $(B=$ $-.21, p=.215$ ) social support from friends, marginalization was found to be not significantly associated with adaptation. In another study, Llamas et al. (2018) found that, among Latina/o undergraduates in the United States, social support obtained from friends served as a protective factor in psychological distress and marginalization. Among sexual minorities, Ceglarek and Ward (2016) reported that high perceived social support was correlated with low number of mental health symptoms.

\section{Social Support and Academic Achievement}

The focus of 3 of the 30 studies reviewed was on studying social support and academic achievement. Overall, among male undergraduates, social support was found to be associated with academic achievement, and the association reported in the included studies was positive. Li et al. (2018), studying undergraduates in China, found that among male undergraduates, there was a significant path from social support towards students' self-esteem $(\beta=.47, p<.01)$, which was then found to have a significant path towards academic achievement $(\beta=.18, p<$ $.01)$.

Similar positive impact of social support on students' academic achievement was found in a study conducted by Bai et al. (2018) in Hong Kong among undergraduates learning English. Specifically, significant correlation was reported between English learning academic achievement, self-efficacy, and social support. Positive social support from teachers $(r=.19$, $p<.01)$, from parents $(r=.25, p<.01)$, and from friends $(r=.13, p<.01)$ were all found to be positively correlated with achievement scores of the students. On the contrary, negative correlation was found between negative social support from parents $(r=-.12, p<.01)$ and friends $(r=-.13, p<.01)$ and achievement scores of the students. Of all the English learning achievement variation, $6 \%$ to $29 \%$ was possible to account between different models on the basis of support from teachers $(r=.29, p<.01)$, negative support from friends $(r=-.14, p<$ $.01)$, positive support from friends $(r=.16, p<.01)$, negative support from parents $(r=-.12, p$ $<.01)$, and positive support from parents $(r=.33, p<.01)$. A more indirect impact than this of social support on academic achievement was reported by Rodríguez et al. (2017) in the context of Spanish students, as social support was found to impact student achievement via adjustment, where social support explained $30.3 \%$ variation in adjustment. 


\section{Social Support and Technology Use}

PROBLEMS

OF EDUCATION

IN THE $21^{\text {st }}$ CENTURY

Vol. 78 , No. 2, 2020

243

The focus of 4 of the 30 studies reviewed was on studying social support and technology use. Positive impact of technology for seeking social support was reported by Deechuay et al. (2016), who found that, among undergraduates in Bangkok, male undergraduates were more likely to experience peer social support through technology $(F=12.31$, partial eta squared $=.015$, $p<.01$ ). Additionally, it was found that social support had positive impact on the negative consequences of technology. Zhang et al. (2018), who studied Internet addiction among undergraduates in China, found that, among male undergraduates addicted to Internet, social support, measured across three sources, namely teacher, peer, and family support, was related to emotional regulation (teacher $b=.18, p<.001$; peer $b=.44, p<.001$; family $b=.29, p$ $<.001$ ) and self-efficacy (teacher $b=.45, p<.001$; peer $b=.23$, $p<.001$; family $b=.26, p$ $<.001)$. Internet addiction was also examined in the context of social support by Shah et al. (2016), albeit in the context of undergraduates in Pakistan. Across three periods, the researchers reported that the indirect impact of social support in the first period on internet addiction at third period through second period variable of loneliness was -0.07 ( $p<.05,95 \%$ CI: -0.13 to -0.02$)$. Gökçearslan et al. (2018), who studied smartphone addiction, found moderate social support $(X$ $=4.79)$ associated with low smartphone addiction $(X=2.79)$.

\section{Sources of Social Support}

The focus of 4 of the 30 studies reviewed was on studying sources of social support. There were variations with respect to different sources. For instance, Bhochhibhoya et al. (2017) found differences in mean scores between four social support sources within those United States-based International students, namely those who were close to participants in nearby community who were native to United States (17.37 \pm 8.04$)$, those who were close to participants based in the United States but hailing from outside (17.42 \pm 7.54), those who were acquainted with the research participants based in the United States hailing from the same ancestral nation as that of the students $(21.13 \pm 8.14)$, and those acquainted with the participants based in the student's ancestral nation (25.25 \pm 6.87$)$. It was found that social support obtained from those close to the participants living in their ancestral nation was higher compared to those who were close to participants based in the United States hailing from the ancestral nation of the students $(p<.01$, Cohen's $d=0.54)$, those who were acquainted with participants based in the United States hailing from outside ( $p<.01$, Cohen's $d=1.08$ ), and those who were acquainted with participants who were native to United States and living in community nearby $(p<.01$, Cohen's $d=1.05)$.

A similar inquiry, albeit in the context of Malaysian undergraduates, was conducted by Chuah and Singh (2016), who studied social support experienced by international students from the source of host nation's students and found that international students expected to communicate and share their joys with host students (mean 2.80), and it was found that $77 \%$ of international students felt accepted and viewed host nation's students as sources of social support. Sources of social support were examined among undergraduate sexual and racial minorities in the United States by Rios and Eaton (2016). Findings revealed that $79 \%$ of the students named both heterosexual and homosexual reported men as social support sources, including friends, uncles, cousins, brothers, and fathers. Additionally, $75 \%$ reported women as sources of social support, including sisters, cousins, aunts, friends, mothers, and grandmothers. Three sources of social support were examined by Lee and Goldstein (2016), namely romantic partners, friends, and family, in terms of their impact on undergraduates' loneliness. It was found that romantic partners and friends always had negative correlation with loneliness $(p<$ .001). However, it was found that social support from family was not effective with respect to loneliness. 
James MORRIS III. Social support among male undergraduates: A systematic review

PROBLEMS

OF EDUCATION

IN THE $21^{\text {st }}$ CENTURY Vol. 78 , No. 2, 2020

244

\section{Gender Differences in Social Support}

The focus of 3 of the 30 studies reviewed was on studying gender differences in social support. There were variations with respect to gender differences. Zamani-Alavijeh et al. (2017), who studied Iranian undergraduates, found that male mean score regarding social support received based on perception was higher $(p=.02)$. Among undergraduates in China, Zhang et al. (2018) found that, among male undergraduates, there was a stronger correlation between distress (-0.18) and resilience compared to social support and resilience (-0.16). Among females, stronger correlation was found between distress and social support $(-0.31)$ than distress and resilience (0.01). Finally, Lin (2016), who studied Taiwanese undergraduates, found gender differences with respect to social support $(t=-6.63, p=.001)$, with female students showing higher scores for social support than males.

\section{Discussion}

Five broad categories were identified within which the recent literature on social support among male undergraduates had been conducted, namely psychological outcomes, academic achievement, technology use, sources of social support, and gender differences in social support. Overall, the impact of social support on all variables related to psychological outcomes was found to be positive, with findings showing negative correlation between social support and depression (Abu-Kaf et al., 2018; Roohafza et al., 2016; Tang \& Dai, 2018; Vungkhanching et al., 2016), anxiety (Roohafza et al., 2016; Vungkhanching et al., 2016), stress (Marhamah \& Hamzah, 2016; Vungkhanching et al., 2016), neuroticism (Roohafza et al., 2016), negative effects (Wang et al., 2016) and positive correlation between social support and sense of coherence (Bíró et al., 2016), relationship status (Adamczyk, 2015), positive effects (Wang et al., 2016), workplace engagement (Kim et al., 2016), emotional regulation (You et al., 2017), fewer mental health symptoms (Ceglarek \& Ward, 2016) and cultural adaptation (Ng et al., 2017). Social support emerged as a predictor of emotional distress (Llamas et al., 2018; Wongtongkam, 2019), stress (Yıldırım et al., 2017), marginalization (Llamas et al., 2018) and cultural adaptation (Ng et al., 2017). These findings were reported from diverse range of regions and cultures, representing male undergraduates from countries such as Australia (Wongtongkam, 2019), Belgium (Frison \& Eggermont, 2015), China (Tang \& Dai, 2018; Wang et al., 2016), Hong Kong (Ng et al., 2017), Hungary (Bíró et al., 2016), Indonesia (Marhamah \& Hamzah, 2016), Iran (Roohafza et al., 2016), Israel (Abu-Kaf et al., 2018), Korea (Kim et al., 2016; You et al., 2017), Poland (Adamczyk, 2015), Turkey (Y1ldırım et al., 2017), and United States (Ceglarek \& Ward, 2016; Llamas et al., 2018; Vungkhanching et al., 2016). Additionally the studies were also diverse in terms of the size of male undergraduates represented in the sample, ranging from 9 (Bíró et al., 2016) to 40 (Vungkhanching et al., 2016), 41 (Ceglarek \& Ward, 2016), 69 (Wongtongkam, 2019), 75 (Abu-Kaf et al., 2018), 80 (Kim et al., 2016), 97 (Ng et al., 2017), 99 (Y1ldırım et al., 2017), 137 (Llamas et al., 2018), 148 (Adamczyk, 2015), 149 (Marhamah \& Hamzah, 2016), 438 (Frison \& Eggermont, 2015), 622 (You et al., 2017), 883 (Tang \& Dai, 2018), 958 (Wang et al., 2016), and 2106 (Roohafza et al., 2016).

With respect to the impact of social support on variables related to academic achievement, it is also found to be positive, although the findings differ with respect to whether the impact is direct or indirect. For instance, Bai et al. (2018) reported direct positive correlation between social support from teachers, parents, and friends and achievement scores of the students, and direct negative correlation between social support from parents and friends and achievement scores of the students. On the contrary, Li et al. (2018) found an indirect path from social support to academic achievement via students' self-esteem. Rodríguez et al. (2017) also reported indirect impact of social support, showing that social support impacted student achievement 
via adjustment. These findings were also reported from diverse range of regions and cultures, representing male undergraduates from countries like Hong Kong (Bai et al., 2018), China (Li et al., 2018), and Spain (Rodríguez et al., 2017). Likewise, the studies differed in terms of the size of male undergraduates represented in the sample, ranging from 102 (Rodríguez et al., 2017) to 108 (Li et al., 2018) and 620 (Bai et al., 2018).

Regarding the association between social support and technology use, researchers reported positive impact of social support on technology, whether in the form of help-seeking behavior or addiction. For instance, Deechuay et al. (2016) found social support had positive impact on the negative consequences of technology, as male undergraduates were more likely to experience peer social support through technology, while three studies focused on technology addiction (Gökçearslan et al., 2018; Shah et al., 2016; Zhang et al., 2018) all reported positive impact of social support on technology-related outcomes. Zhang et al. (2018) found that among male undergraduates addicted to Internet, social support was related to emotional regulation and self-efficacy, while Shah et al. (2016) found a more indirect effect of social support on internet addiction. Another form of addiction studied was smartphone addiction, where social support was found to be associated with low smartphone addiction (Gökçearslan et al., 2018). These findings were also reported from diverse range of regions and cultures, representing male undergraduates from countries like China (Zhang et al., 2018), Thailand (Deechuay et al., 2016), Pakistan (Shah et al., 2016), and Turkey (Gökçearslan et al., 2018). The studies differed in terms of the size of male undergraduates represented in the sample, ranging from 81 (Zhang et al., 2018) to 82 (Shah et al., 2016), 231 (Deechuay et al., 2016), and 364 (Gökçearslan et al., 2018).

Regarding the sources of social support, a diverse range of sources of social support is discovered among a diverse range of sample. Among American international undergraduate students, sources of social support included individuals who were acquainted with students in nearby community who were native to United States, individuals who were acquainted with students based in the United States originally hailing from outside, individuals who were acquainted with students based in the United States originally hailing from the students' ancestral nation, and individuals acquainted with students based in their ancestral nation (Bhochhibhoya et al., 2017). Among Malaysian international undergraduate students, host nation's students emerged as a major source of social support (Chuah and Singh, 2016). Among American homosexual male undergraduate students, sources of social support included both heterosexual and homosexual men, including friends, uncles, cousins, brothers, and fathers (Rios \& Eaton, 2016). Romantic partners, friends, and family were other sources of social support found among the general population of male undergraduates (Lee \& Goldstein, 2016). Researchers also report some variations based on gender in the context of social support, as findings showed that male mean score regarding social support received based on perception was higher in Iran (ZamaniAlavijeh et al., 2017), but in Taiwan, female students showed higher scores for social support compared to males (Lin, 2016). There was a stronger correlation reported between distress and resilience among males compared to social support and resilience in China (Zhang et al., 2018).

\section{Conclusions and Implications}

The purpose in this systematic review was to help obtain an understanding of existing knowledge on social support among male undergraduates based on a systematic review of relevant recent literature. The research question guiding the systematic review of literature focused on examining the findings that could be identified from the recent literature on social support among male undergraduates. To search for relevant literature, a search strategy was developed, consisting of six criteria, which was then implemented on multiple databases. After excluding the studies that did not meet the inclusion criteria, a total of 30 studies were found that adhered to the inclusion criteria set for the systematic review. 
PROBLEMS

OF EDUCATION

IN THE $21^{\text {st }}$ CENTURY

Vol. 78, No. 2,2020

246

The findings of the study showed that the impact of social support on all variables related to psychological outcomes was positive, with findings showing negative correlation between social support and depression, anxiety, stress, neuroticism, negative effects and positive correlation between social support and sense of coherence, relationship status, positive effects, workplace engagement, emotional regulation, fewer mental health symptoms, and cultural adaptation. With respect to the impact of social support on variables related to academic achievement, it was also found to be positive, although the findings differed with respect to whether the impact was direct or indirect. Regarding the association between social support and technology use, researchers reported positive impact of social support on technology, whether in the form of help-seeking behavior or addiction. Regarding the sources of social support, a diverse range of sources of social support were discovered among a diverse range of sample. Researchers also reported some variations based on gender in the context of social support.

The findings of this study have implications for both research and practice. In addition to addressing a gap in the literature on the lack of systematic reviews examining the current state of research on male undergraduates with respect to social support, findings such as variations based on gender, positive impact of social support on male undergraduates' psychological outcomes, academic achievement, and technology use may also help teachers, educational policymakers, educators, and scholars identify the most relevant patterns in the literature on social support among male undergraduates that could then be used to note important dimensions within which possible interventions could be introduced to promote desired outcomes. A limitation of the present systematic review was the fact that, due to the high variation found among the studies regarding measures and samples, it was not feasible to conduct a meta-analysis. It is recommended that future researchers consider conducting a meta-analysis on the role of social support among undergraduate males. Additionally, the findings revealed variations in social support among male undergraduate students based on the countries in which the studies were conducted. In this regard, future researchers may also consider conducting comparative studies to examine specific variations in social support among male undergraduates based on countries.

\section{References}

Abu-Kaf, S., Shahar, G., Noyman-Veksler, G., \& Priel, B. (2018). Role of perceived social support in depressive and somatic symptoms experienced by Bedouin Arab and Jewish Israeli undergraduates. Transcultural Psychiatry, 56(2), 359-378. https://doi. org $/ 10.1177 / 1363461518808948$

Adamczyk, K. (2015). An investigation of loneliness and perceived social support among single and partnered young adults. Current Psychology, 35(4), 674-689. https://doi.org/10.1007/s12144-0159337-7

Bai, B., Chao, G., \& Wang, C. (2018). The relationship between social support, self-efficacy, and English language learning achievement in Hong Kong. TESOL Quarterly, 53(1), 208-221. https://doi. org/10.1002/tesq.439

Bhochhibhoya, A., Dong, Y., \& Branscum, P. (2017). Sources of social support among international college students in the United States. Journal of International Students, 7(3), 671-686.

Bíró, É., Veres-Balajti, I., \& Kósa, K. (2016). Social support contributes to resilience among physiotherapy students: a cross sectional survey and focus group study. Physiotherapy, 102(2), 189-195. https:// doi.org/10.1016/j.physio.2015.05.002

Ceglarek, P., \& Ward, L. (2016). A tool for help or harm? How associations between social networking use, social support, and mental health differ for sexual minority and heterosexual youth. Computers in Human Behavior, 65, 201-209. https://doi.org/10.1016/j.chb.2016.07.051

Chuah, J., \& Singh, M. (2016). International students' perspectives on the importance of obtaining social support from host national students. International Education Studies, 9(4), 132-140. https://doi. org/10.5539/ies.v9n4p132 
Deechuay, N., Koul, R., Maneewan, S., \& Lerdpornkulrat, T. (2016). Relationship between gender Vol. 78 , No. 2, 2020 identity, perceived social support for using computers, and computer self-efficacy and value beliefs of undergraduate students. Education and Information Technologies, 21(6), 1699-1713. https://doi.org/10.1007/s10639-015-9410-8

Frison, E., \& Eggermont, S. (2015). Exploring the relationships between different types of Facebook use, perceived online social support, and adolescents' depressed mood. Social Science Computer Review, 34(2), 153-171. https://doi.org/10.1177/0894439314567449

Gökçearslan, Ş., Uluyol, Ç., \& Şahin, S. (2018). Smartphone addiction, cyberloafing, stress and social support among university students: A path analysis. Children and Youth Services Review, 91, 4754. https://doi.org/10.1016/j.childyouth.2018.05.036

Kim, N., Kim, H., \& Lee, K. (2016). Social support and occupational engagement among Korean undergraduates. Journal of Career Development, 45(3), 285-298. https://doi. org/10.1177/0894845316682319

Lee, C., \& Goldstein, S. (2016). Loneliness, stress, and social support in young adulthood: Does the source of support matter? Journal of Youth and Adolescence, 45(3), 568-580. https://doi.org/10.1007/ s10964-015-0395-9

Li, J., Han, X., Wang, W., Sun, G., \& Cheng, Z. (2018). How social support influences university students' academic achievement and emotional exhaustion: The mediating role of self-esteem. Learning and Individual Differences, 61, 120-126. https://doi.org/10.1016/j.lindif.2017.11.016

Lin, C. (2016). The roles of social support and coping style in the relationship between gratitude and well-being. Personality and Individual Differences, 89, 13-18. https://doi.org/10.1016/j. paid.2015.09.032

Llamas, J., Morgan Consoli, M., Hendricks, K., \& Nguyen, K. (2018). Latino/a freshman struggles: Effects of locus of control and social support on intragroup marginalization and distress. Journal of Latina/O Psychology, 6(2), 131-148. https://doi.org/10.1037/lat0000089

Marhamah, F., \& Hamzah, H. (2016). The relationship between social support and academic stress among first year students at Syiah Kuala University. Jurnal Psikoislamedia, 1(1), 149-172.

Ng, T., Wang, K., \& Chan, W. (2017). Acculturation and cross-cultural adaptation: The moderating role of social support. International Journal of Intercultural Relations, 59, 19-30. https://doi. org/10.1016/j.ijintrel.2017.04.012

Rios, D., \& Eaton, A. (2016). Perceived social support in the lives of gay, bisexual and queer Hispanic college men. Culture, Health \& Sexuality, 18(10), 1093-1106. https://doi.org/10.1080/13691058 .2016 .1150516

Rodríguez, M., Tinajero, C., \& Páramo, M. (2017). Pre-entry characteristics, perceived social support, adjustment and academic achievement in first-year Spanish university students: A path model. The Journal of Psychology, 151(8), 722-738. https://doi.org/10.1080/00223980.2017.1372351

Roohafza, H., Feizi, A., Afshar, H., Mazaheri, M., Behnamfar, O., Hassanzadeh-Keshteli, A., \& Adibi, P. (2016). Path analysis of relationship among personality, perceived stress, coping, social support, and psychological outcomes. World Journal of Psychiatry, 6(2), 248-256. https://doi.org/10.5498/ wjp.v6.i2.248

Shah, I., Siddiqui, F., \& Ansari, S. (2016). Relationship between internet addiction and social support among university undergraduates. International Research Journal of Arts and Humanities, 44(44), 209-214.

Tang, W., \& Dai, Q. (2018). Depressive symptoms among first-year Chinese undergraduates: The roles of socio-demographics, coping style, and social support. Psychiatry Research, 270, 89-96. https:// doi.org/10.1016/j.psychres.2018.09.027

Vungkhanching, M., Tonsing, J., \& Tonsing, K. (2016). Psychological distress, coping and perceived social support in social work students. British Journal of Social Work, 47(7), 1999-2013. https:// doi.org/10.1093/bjsw/bcw145

Wang, C., Sun, X., \& Wang, F. (2016). The influence of emotional intelligence and perceived social support on subjective well-being of undergraduate nursing students. China Journal of Health Psychology, 12, 12-19.

Wongtongkam, N. (2019). Influence of coping, self-esteem and social support on undergraduate students' emotional distress. Health Education, 119(3), 187-201. https://doi.org/10.1108/he-01-2019-0001 
James MORRIS III. Social support among male undergraduates: A systematic review

PROBLEMS

OF EDUCATION

IN THE $21^{\text {st }}$ CENTURY

Vol. 78 , No. 2,2020

Yıldırım, N., Karaca, A., Cangur, S., Acıkgoz, F., \& Akkus, D. (2017). The relationship between educational stress, stress coping, self-esteem, social support, and health status among nursing students in Turkey: A structural equation modeling approach. Nurse Education Today, 48, 33-39. https://doi.org/10.1016/j.nedt.2016.09.014

You, S., Lim, S., \& Kim, E. (2017). Relationships between social support, internal assets, and life satisfaction in Korean adolescents. Journal of Happiness Studies, 19(3), 897-915. https://doi. org/10.1007/s10902-017-9844-3

Zamani-Alavijeh, F., Raeesi Dehkordi, F., \& Shahry, P. (2017). Perceived social support among students of medical sciences. Electronic Physician, 9(6), 4479-4488. https://doi.org/10.19082/4479

Zhang, M., Zhang, J., Zhang, F., Zhang, L., \& Feng, D. (2018). Prevalence of psychological distress and the effects of resilience and perceived social support among Chinese college students: Does gender make a difference? Psychiatry Research, 267, 409-413. https://doi.org/10.1016/j. psychres.2018.06.038

Zhang, S., Tian, Y., Sui, Y., Zhang, D., Shi, J., \& Wang, P. et al. (2018). Relationships between social support, loneliness, and internet addiction in Chinese postsecondary students: A longitudinal cross-lagged analysis. Frontiers in Psychology, 9(1707), 1-13. https://doi.org/10.3389/fpsyg.2018.01707

Received: January 27, 2020

Accepted: March 30, 2020

Cite as: Morris III, J. (2020). Social support among male undergraduates: A systematic review. Problems of Education in the $21^{\text {st }}$ Century, 78(2), 235-248. https://doi.org/10.33225/pec/20.78.248

James Morris III

PhD, Lewis University, Psychology Department, Romeoville, Illinois, United

States.

E-mail: professorjmiii@gmail.com

ORCID: 0000-000107251-3794 